\title{
Protective Effect of Potential Probiotic Strains from Fermented Ethiopian Food against Salmonella Typhimurium DT104 in Mice
}

\author{
Guesh Mulaw (D), ${ }^{1,2}$ Diriba Muleta ${ }^{D},{ }^{3}$ Anteneh Tesfaye, ${ }^{3}$ and Tesfaye Sisay ${ }^{3}$ \\ ${ }^{1}$ Department of Microbial, Cellular and Molecular Biology, College of Natural and Computational Sciences, \\ Addis Ababa University, Addis Ababa 1176, Ethiopia \\ ${ }^{2}$ Biology Department, College of Natural and Computational Sciences, Aksum University, Axum 1010, Ethiopia \\ ${ }^{3}$ Institute of Biotechnology, Addis Ababa University, Addis Ababa 1176, Ethiopia \\ Correspondence should be addressed to Guesh Mulaw; guesh2001@gmail.com
}

Received 7 July 2019; Revised 18 February 2020; Accepted 10 March 2020; Published 14 April 2020

Academic Editor: Simona Nardoni

Copyright (c) 2020 Guesh Mulaw et al. This is an open access article distributed under the Creative Commons Attribution License, which permits unrestricted use, distribution, and reproduction in any medium, provided the original work is properly cited.

\begin{abstract}
Salmonella is one of the most harmful pathogens responsible for foodborne outbreaks, illnesses and deaths. The aim of this study was to evaluate the effect of potentially probiotic strains against Salmonella Typhimurium DT104 in mice. The compatibility test among the selected potential probiotic strains (Lactobacillus plantarum K132, Lactobacillus paracasei K114 and Lactococcus lactis E124) using the cross-streaking method showed the absence of antagonism. The anti-Salmonella activities of coculture of the isolated potential probiotics in the form of mixed or single culture showed a remarkable anti-Salmonella activity with 96.50 to $100 \%$ growth inhibition. The combination of strains, which showed the highest growth inhibition rates against Salmonella Typhimurium DT104, was used to test their effect on the colonization of mice by Salmonella Typhimurium DT104. White albino male mice were pretreated with the mixed potential probiotics for 7 days and infected with Salmonella Typhimurium DT104 for 1 day. A total of 3 treatments were applied, during which the negative control group was treated with phosphate-buffered saline (PBS); a positive control group (typ) was challenged with Salmonella Typhimurium DT104 alone. The treated group (pro-typ) was pretreated with mixed potential probiotic culture and then infected with Salmonella Typhimurium DT104. The survival rate of mice and counts of Salmonella in feces were recorded. The survival rate of mice on day 21 after the oral challenge with Salmonella Typhimurium DT104 was significantly $(p<0.05)$ higher in the experimental pro-typ group (100\% survival) compared with the positive control group (20\% survival). The counts (colony-forming unit per $\mathrm{ml}$ ) of Salmonella in feces were significantly lower $(p<0.05)$ for the pro-typ group compared to the typ group. The combination of potential probiotic strains was able to protect mice against Salmonella Typhimurium DT104 infection that demonstrates their potential to be used as probiotic cultures for the production of functional fermented products.
\end{abstract}

\section{Introduction}

Foodborne diseases (FBDs) pose a severe public health problem that significantly affects people's wellbeing and leads to serious socioeconomic implications [1]. The major foodborne bacterial pathogens are Campylobacter jejuni, Clostridium perfringens, Escherichia coli, Listeria monocytogenes, Salmonella spp. and Staphylococcus aureus [2]. These pathogens have developed multiple drug resistance and cause great economic losses in developing as well as developed countries [3]. The problem of foodborne diseases is multifactorial, and their prevention and control require multidisciplinary approaches [4].

Among the major foodborne pathogens, Salmonella enterica is one of the leading causes of serious illness ranging from acute gastroenteritis to systemic infections including typhoid [5]. Oral infection with Salmonella Typhimurium in mice provokes a disease similar to that caused by Salmonella Typhi in humans, with fever, enteritis, and septicemia which is lethal to the host [6]. However, the nature and severity of the infection developed depends on many factors, including the serovar involved, the virulence of the strain, the infective 
TABle 1: Source of probiotic strains and Salmonella Typhimurium used in this investigation.

\begin{tabular}{lcccc}
\hline Number & Designation & PROB1806 & Strains & Source of isolation \\
\hline 1 & E 124 & E8 & Lactococcus lactis & Ergo \\
2 & K114 & G9 & Lactobacillus paracasei & Kocho \\
3 & K132 & H8 & Lactobacillus plantarum & Kocho \\
4 & DT104 & ATCC & Salmonella Typhimurium & EPHI \\
\hline
\end{tabular}

$\mathrm{E}=$ ergo and $\mathrm{K}=$ kocho; EPHI: Ethiopian Public Health Institute.

dose, the age and immune status of the host. Therefore, it is estimated that Salmonella species cause 93.8 million gastroenteritis infections worldwide and resulted in 155000 deaths each year [7].

Currently, vaccination and antibiotics are used to prevent and control Salmonella infections. Accordingly, antibiotic applications are the common clinical treatments for Salmonella infection which, in turn, promotes the development of resistant Salmonella species towards antibiotics [8]. In addition, the prolonged use of antibiotics leads to changes in the intestinal commensal microflora [9]. Due to the occurrence of multidrug-resistant strains and the suboptimal efficacy of currently available vaccines, alternative intervention strategies against Salmonella infections are urgently needed [10-12]. One of the promising alternative control approaches is the possible beneficial use of probiotics against various pathogens, including Salmonella spp. [13].

The consumption of a large number of probiotics (live microorganisms) together with food item can fundamentally promotes the health of the consumers [14]. The possible mechanisms, by which probiotics protect against enteric pathogen infections, are the production of antimicrobial substances, competition for limited resources, and antiadhesive effects [15]. A great number of in vivo and in vitro studies have been carried out to evaluate the effect of probiotics in the prevention and treatment of gastrointestinal infections caused by Salmonella species [16-18]. The beneficial effects of the probiotics are known to be genus, species and strain specific [19-21]. Currently, food-based probiotics have supposed greater significance as different food products can harbor native and beneficial probiotics and therefore can be used for both nutritional and therapeutic purposes [22].

Ethiopian fermented food products are well known for their unique fermentation style and can be used as a source of potentially beneficial probiotics. Tesfaye et al. [18] revealed the antagonistic effect of lactic acid bacterial strains either as pure or defined mixed cultures against some foodborne pathogens during fermentation and storage of fermented milk. There are still few research data available on the characterization of probiotic LAB from Ethiopian traditional fermented foods. Most of the traditionally fermented products of Ethiopia are consumed without further heat processing which can be considered as ideal vehicles to carry probiotic bacteria into the human gastrointestinal tract. Probiotic strains isolated from traditionally fermented foods and drinks could have a desirable functional property for their application as probiotics against foodborne pathogens. Thus, the main objective of this study is to test the effect of three potentially probiotic strains of LAB isolated from traditionally Ethiopian fermented ergo and kocho products against Salmonella Typhimurium under in vivo conditions using laboratory animal.

\section{Materials and Methods}

2.1. Bacterial Strains and Growth Condition. The bacterial strains and sources of isolation used in this study are listed in Table 1. The potential probiotic strains were isolated from traditionally fermented kocho and ergo products. These strains were identified as Lactobacillus plantarum K132, Lactobacillus paracasei K114 and Lactococcus lactis E124 by whole genome sequencing in the Earlham Institute (Norwich, UK) (unpublished data). All of the strains were Gram-positive and catalasenegative and were able to grow on MRS agar. Salmonella Typhimurium DT104 was obtained from Ethiopian Public Health Institute (EPHI), Addis Ababa, Ethiopia (Table 1). Salmonella Typhimurium DT104 was able to grow aerobically in xylose-lysine-deoxycholate (XLD) agar for $24 \mathrm{~h}$ at $37^{\circ} \mathrm{C}$.

2.2. Compatibility between Probiotic Strains. The compatibility of the selected potential probiotic strains was examined by a cross-streak method as previously described by Pedersen and Tannock [23]. Overnight cultures of the isolates were streaked perpendicularly by forming across with each other on MRS agar plates. The plates were incubated at $37^{\circ} \mathrm{C}$ for 48 hours anaerobically using an anaerobic jar. The type of growth in the confluence zones (stimulation, inhibition, or absence of interaction between the strains) was visually determined [24]. The presence of growth inhibitory halos indicates incompatibility between strains.

2.3. Coculture Assay. To evaluate the effect of selected potential pure strains (Lactococcus lactis E124, Lactobacillus paracasei K114 and Lactobacillus plantarum K132) and their combinations on the growth of Salmonella Typhimurium DT104, liquid coculture technique was used as described by Potočnjak et al. [25] with some modifications. Before cocultivation, the selected strains and Salmonella Typhimurium DT104 were grown separately in de Man, Rogosa, and Sharpe (MRS) broth and tryptic soy broth (TSB), respectively. Thus, $100 \mu \mathrm{l}$ of each and mixed strains (a total of $\left.10^{6} \mathrm{CFU} / \mathrm{mL}\right)$ and of S. Typhimurium $\left(10^{4} \mathrm{CFU} / \mathrm{mL}\right)$ were inoculated into brain heart infusion (BHI) broth and incubated for $24 \mathrm{~h}$ at $37^{\circ} \mathrm{C}$ in aerobic conditions. The control was a monoculture of $S$. Typhimurium. The number of Salmonella was determined by plate count agar on the xylose-lysine-deoxycholate (XLD) solid medium. Experiments were carried out in triplicate. The inhibition percentage was calculated according to the following equation [26]: 
TABle 2: Preparation of pure and mixed potential probiotic LAB cultures for the coculture assay.

\begin{tabular}{|c|c|c|}
\hline No. & Isolate code & $\begin{array}{l}\text { Pure and mixed potential probiotic LAB } \\
\text { strains }\end{array}$ \\
\hline 1 & E124 & Lactococcus lactis \\
\hline 2 & K & Lactobacillus plantarum \\
\hline 3 & K114 & Lactobacillus paracasei \\
\hline 4 & $\mathrm{E} 124+\mathrm{K} 320$ & Lac. lactis + Lb. plantarum (mix 1$)$ \\
\hline 5 & $\mathrm{E} 124+\mathrm{K} 114$ & Lac. lactis $+L b$. paracasei (mix 2) \\
\hline 6 & $\mathrm{~K} 320+\mathrm{K} 114$ & $L b$. plantarum $+L b$. paracasei $(\operatorname{mix} 3)$ \\
\hline 7 & $\mathrm{E} 124+\mathrm{K} 114$ & $\begin{array}{l}\text { Lac. lactis }+L b . \text { plantarum }+L b . \text { paracasei } \\
(\operatorname{mix} 4)\end{array}$ \\
\hline
\end{tabular}

$\mathrm{E}=\operatorname{ergo} ; \mathrm{K}=$ kocho.

inhibition $(\%)$

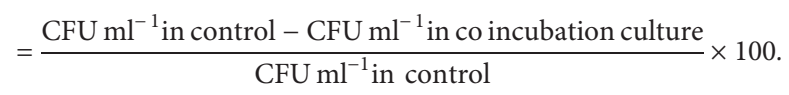

Therefore, the preparation of pure and mixed probiotic $\mathrm{LAB}$ cultures for the coculture assay is presented in Table 2.

\subsection{In Vivo Antagonistic Effect of Mixed Probiotic Strains against Salmonella Infection}

2.4.1. Experimental Mice. Four to six weeks aged male white albino mice were obtained from the Animal House of the Department of Microbial, Cellular and Molecular Biology, Addis Ababa University. Mice were housed in cages in the animal room. These mice were provided with standard diet and water ad libitum. The bedding of mice was changed every three days, and the health status of the animals was monitored regularly.

2.4.2. Experimental Design. A total of 30 male white albino mice were used in the study. Five mice per cage were randomly congregated into three groups. Group I served as a negative control and was treated with phosphate-buffered saline (PBS). Group II was challenged with mono Salmonella Typhimurium DT104 culture (positive control, typ). Protection against Salmonella Typhimurium DT104 infection by administration of mixed probiotic cultures was evaluated in Group III (pro-typ). Fecal samples from each group were pooled and checked for a week for the absence/presence of Salmonella. Five gram (g) of fecal material was homogenized into $45 \mathrm{ml}$ of sterile $0.1 \%$ buffered peptone water and $25 \mathrm{ml}$ was further enriched in $225 \mathrm{ml}$ of tryptic soya broth. Enriched cultures were streaked on XLD plates. After ensuring the absence of Salmonella spp. from all groups of mice, Salmonella Typhimurium DT104 and various LAB cultures were administered to mice after depriving the mice water a day before as indicated by Truusalu et al. [27].

2.4.3. Treatments Preparation. The best performing potential probiotic strains in a liquid coculture assay were selected for an in vivo test using a mouse model. Consequently, in vivo evaluation of the probiotic effect of the mixed potential probiotic strains (Lactococcus lactis E124, Lactobacillus paracasei K114 and Lactobacillus plantarum K132) against S. Typhimurium DT104 was done via oral inoculation of mice following the protocol given in Chen et al. [28]. The experiment was conducted twice, and the average was used for analysis.

Probiotic cultures were separately grown overnight at $37^{\circ} \mathrm{C}$ in $10 \mathrm{ml}$ of MRS broth. To prepare the mixed culture, the overnight growth of each culture $(10 \mathrm{ml})$ was quantified by serial dilution and plate counting to get $\log 6 \mathrm{CFUml}^{-1}$ that achieved by mixing equal volumes of each strain and was divided into daily portions of combined strains. Prior to the feeding step, the mixed culture was prepared by mixing $\log 6 \mathrm{CFUml}^{-1}$ of each of the potential probiotic strains. Hence, the mixed potential probiotic strains (Lactobacillus plantarum K132, Lactobacillus paracasei K114 and Lactococcus lactis E124) were termed as a multi-strain formula (MFA). Salmonella Typhimurium DT104 was grown separately overnight at $37^{\circ} \mathrm{C}$ in $10 \mathrm{ml}$ of tryptic soya broth. Overnight growth of LAB cultures and cultures of $S$. Typhimurium DT104 were separately serially diluted in $10 \mathrm{ml}$ of sterile $0.1 \%$ buffered peptone water to give $10^{4} \mathrm{CFUml}^{-1}$.

The experiment was divided into 3 stages [29]: the initial stage (day 1 to 7 ), the infection stage (day 8), and the final stage (day 9 to 21 ). Group I mice were given $0.3 \mathrm{ml}$ of phosphate-buffered saline (PBS) for the whole 7 days. Group II mice were challenged with mono Salmonella Typhimurium DT104 at day 8 with a dose $\left(0.3 \mathrm{ml} ; 4 \log \mathrm{CFU} \cdot \mathrm{mL}^{-1}\right.$ of viable organism) as one oral dose. Protection against Salmonella Typhimurium DT104 infection by administration of mixed probiotic strains was evaluated in Group III. In this Group, mixed LAB strains $\left(0.3 \mathrm{ml}\right.$ per day; $\left.6 \log \mathrm{CFU} \cdot \mathrm{mL}^{-1}\right)$ were given using a sterile syringe blunt-ended tube for consecutive 7 days and at the day 8 , they were orally administered with Salmonella Typhimurium DT104 $(0.3 \mathrm{ml} ; 4$ logs CFU.mL $\mathrm{m}^{-1}$ of viable organism) as one oral dose. The symptoms and deaths of mice were registered, and all the survived animals were killed by cervical dislocation on the $21^{\text {st }}$ day. The percent survival (the number of the alive/total number of mice) was recorded every day for 21 days.

\subsubsection{Viable Cell Counts of Salmonella Typhimurium DT104} in Fecal Material of Mice. Aseptically, freshly voided fecal material of mice was collected daily using sterile forceps from day 9 to day 21. Fecal material $(5 \mathrm{~g})$ from each group was moistened for 10 minutes in $45 \mathrm{ml}$ of $0.1 \%$ buffered peptone water and then homogenized using a Stomacher lab blender (Stomacher 400, Seward, London, UK). Then, appropriate dilutions of each homogenate $(0.1 \mathrm{ml})$ were plated on xyloselysine-deoxycholate (XLD) agar for enumeration of Salmonella Typhimurium DT104. Plates were incubated at $37^{\circ} \mathrm{C}$ for 24 hours, and colony-forming units on the plates were recorded. When counts were $<\log 1 \mathrm{CFU} \cdot \mathrm{mL}^{-1}$, samples were enriched in tryptic soya broth. Each determination was done in triplicate.

\section{Data Analysis}

All experiments were carried out in triplicate. The results were expressed as mean standard deviation (SD). Statistical 
TABLE 3: The interaction between the selected potential probiotic LAB strains.

\begin{tabular}{lcccc}
\hline No & Isolate code & Mixed probiotic strains & Inhibition & Cogrowth \\
\hline 1 & E124-K320 & Lac. lactis-Lb. plantarum & - & + \\
2 & E124-K114 & Lac. lactis-Lb. paracasei & - & + \\
3 & K320-K114 & Lb. plantarum-Lb. paracasei & - & + \\
4 & E124-K320-K114 & Lac. lactis-Lb. plantarum-Lb. paracasei & + \\
\hline
\end{tabular}

$\mathrm{E}=$ ergo; $\mathrm{K}=$ kocho. "-" indicates no inhibition halos against each other; “+” indicates able to exist and perform agreeable.

TABle 4: Coculture assay of probiotic LAB strains against Salmonella Typhimurium DT104.

\begin{tabular}{|c|c|c|c|}
\hline No & Isolate code & Probiotic strains & Inhibition (\%) \\
\hline 1 & E124 & Lactococcus lactis & $97.11 \pm 0.23^{\mathrm{b}}$ \\
\hline 2 & K320 & Lactobacillus plantarum & $96.50 \pm 0.29^{c}$ \\
\hline 3 & K114 & Lactobacillus paracasei & $97.27 \pm 0.26^{\mathrm{b}}$ \\
\hline 4 & $\mathrm{E} 124+\mathrm{K} 320$ & Lac. lactis + Lb. plantarum (mix 1$)$ & $99.71 \pm 0.02^{\mathrm{a}}$ \\
\hline 5 & $\mathrm{E} 124+\mathrm{K} 114$ & Lac. lactis $+L b$. paracasei (mix 2) & $99.74 \pm 0.02^{\mathrm{a}}$ \\
\hline 6 & $\mathrm{~K} 320+\mathrm{K} 114$ & $L b$. plantarum $+L b$. paracasei $(\operatorname{mix} 3)$ & $99.72 \pm 0.01^{\mathrm{a}}$ \\
\hline 7 & $\mathrm{E} 124+\mathrm{K} 320+\mathrm{K} 114$ & Lac. lactis + Lb. plantarum + Lb. paracasei $(\operatorname{mix} 4)$ & $100.00 \pm 0.00^{\mathrm{a}}$ \\
\hline
\end{tabular}

$\mathrm{E}=$ ergo; $\mathrm{K}=$ kocho. Data are means $\pm \mathrm{SD}$ from three replications and values followed by a different letters within columns indicate significant differences $(p<0.05)$.

analysis was performed using SAS software R 9.1 (SAS Institute Japan, Tokyo) and Stat View Ver. 5 (SAS Institute, Cary, NC).

\section{Results}

4.1. Compatibility among Probiotic Strains. Compatibility among 3 selected potential probiotic strains has been determined by cross-streaking the strains (Lactobacillus plantarum K132, Lactobacillus paracasei K114 and Lactococcus lactis E124) on an MRS agar plate (Table 3). Although the selected probiotic strains were confirmed to have antagonistic activity towards the tested pathogen, the 3 selected probiotics LAB strains did not show any inhibition halos against each other, suggesting the absence of antagonism among strains when combined in mixed cultures (Table 3). Generally, the cross-streak assay showed similar results, as no evidence of competition was noticeable at sites of cogrowth in the solid medium in any combination of probiotic strains assayed (Table 3). Finally, after the compatibility experiment, the 3 potential probiotic strains isolated from traditional fermented food products were taken to the next step for the coculture assay study.

4.2. Coculture Assay. All the pure and mixed probiotic LAB strains when separately and/or in combined forms cocultured against the test foodborne pathogen (Salmonella Typhimurium DT104) showed more than 96\% growth inhibition of the test organism (Table 4). The highest coculture antagonistic activity (100\% growth inhibition) was observed with the mixed cultures of the three probiotic strains ( $\operatorname{mix} 4$ ) followed by the combination of two combined probiotic strains in the form of mix 2, mix 3, and mix 1 with $99.74 \%$, $99.72 \%$, and $99.71 \%$ of inhibition, respectively. However, the lowest $(p<0.05)$ growth inhibition $(96.50 \%)$ was shown with the separate pure culture of Lactobacillus plantarum against Salmonella Typhimurium DT104 (Table 4).
4.3. In Vivo Antagonistic Effect of Mixed Probiotic Strains Against Salmonella Infection. The survival rate of the treated group (pro-typ) was $100 \%$, whereas only $20 \%$ of the positive control group that was challenged only with $S$. Typhimurium DT104 survived (Figure 1).

Apparently, day 1 after infection with Salmonella Typhimurium DT104, all the mice in the pro-typ group and positive control group (typ) started to show disease symptoms. Ultimately, hair erection and diarrhea were observed. However, the mice pretreated with the mixed potential probiotic strains were able to recover from sickness, but the mice challenged with Salmonella Typhimurium DT104 alone (positive control group) became sick and finally died. Therefore, in the positive control group (Group II), the first mortality rate $(30 \%)$ was observed at day 3 and at day 5 and the death rate was increased to $50 \%$. As testing time extended beyond five days, the mortality rate was increasing in the positive control. Finally, the mortality rate (80\%) in mice was recorded at the end of day 21 . However, there was no mortality in the negative control Group I only treated with the PBS (Figure 1).

4.4. Viable Cell Count of Salmonella Typhimurium DT104 in Fecal Material of Mice. In the negative control group (PBS) of mice, no viable Salmonella Typhimurium DT104 counts were detected (Table 5). In comparison with the results from Group II, Salmonella-challenged mice that fed on mixed probiotic strains for 7 days reduced the Salmonella cells in the feces when measured from day 9 to day $21 \quad(p<0.05$; Table 5). The findings showed that the CFU count of Salmonella Typhimurium DT104 in mice which were given with mixed probiotics strains were lower than that of the positive control group (Table 5). This shows that the presence of combined probiotic LAB in the gut is able to inhibit the growth of the pathogenic bacterium. On the other hand, in the feces of mice fed with combined probiotic LAB strains, the fecal CFU count of Salmonella Typhimurium 


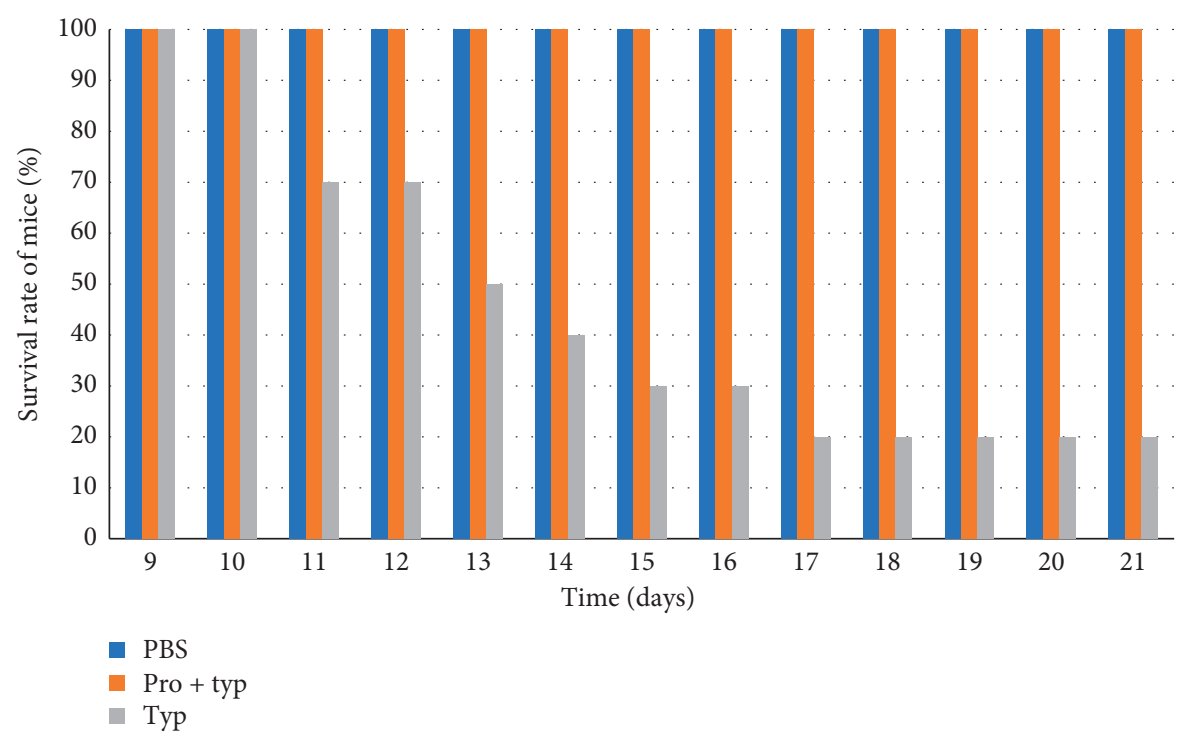

FIGURE 1: Survival of mice treated or not treated with mixed potential probiotic strains and orally infected with Salmonella typhimurium DT104. Means not connected by the same letter are significantly different at $p<0.05$. Results expressed as average $(n=2) \pm$ SD (standard deviation). Legend: $\mathrm{PBS}=$ phosphate-buffered saline; pro + typ = both mixed probiotic cultures and Salmonella; typ = mono Salmonella Typhimurium DT104.

TABLE 5: Viable cell counts of Salmonella Typhimurium DT104 in fecal material of mice.

\begin{tabular}{|c|c|c|c|c|}
\hline \multirow{2}{*}{ Sample } & \multirow{2}{*}{ Sampling days } & \multicolumn{3}{|c|}{ Treatment group } \\
\hline & & Negative control (PBS) & Treated group (pro-typ) & Positive control (typ) \\
\hline \multirow{13}{*}{ Fecal material of mice } & Day 9 & $0.00 \pm 0.00^{\mathrm{a}}$ & $2.27 \pm 0.01^{\mathrm{ab}}$ & $4.47 \pm 0.02^{\mathrm{f}}$ \\
\hline & Day 10 & $0.00 \pm 0.00^{\mathrm{a}}$ & $2.30 \pm 0.03^{\mathrm{a}}$ & $4.52 \pm 0.04^{\mathrm{e}}$ \\
\hline & Day 11 & $0.00 \pm 0.00^{\mathrm{a}}$ & $1.93 \pm 0.04^{\mathrm{abc}}$ & $4.56 \pm 0.01^{\mathrm{bcd}}$ \\
\hline & Day 12 & $0.00 \pm 0.00^{\mathrm{a}}$ & $1.90 \pm 0.07^{\mathrm{abc}}$ & $4.55 \pm 0.02^{\mathrm{cde}}$ \\
\hline & Day 13 & $0.00 \pm 0.00^{\mathrm{a}}$ & $1.88 \pm 0.04^{\mathrm{abc}}$ & $4.58 \pm 0.02^{\mathrm{abc}}$ \\
\hline & Day 14 & $0.00 \pm 0.00^{\mathrm{a}}$ & $1.82 \pm 0.05^{\mathrm{bcd}}$ & $4.61 \pm 0.00^{\mathrm{a}}$ \\
\hline & Day 15 & $0.00 \pm 0.00^{\mathrm{a}}$ & $1.74 \pm 0.06^{\mathrm{cd}}$ & $4.60 \pm 0.01^{\mathrm{a}}$ \\
\hline & Day 16 & $0.00 \pm 0.00^{\mathrm{a}}$ & $1.65 \pm 0.07^{\mathrm{cd}}$ & $4.59 \pm 0.00^{\mathrm{ab}}$ \\
\hline & Day 17 & $0.00 \pm 0.00^{\mathrm{a}}$ & $1.65 \pm 0.07^{\mathrm{cd}}$ & $4.56 \pm 0.01^{\mathrm{bcd}}$ \\
\hline & Day 18 & $0.00 \pm 0.00^{\mathrm{a}}$ & $1.39 \pm 0.13^{\mathrm{d}}$ & $4.56 \pm 0.01^{\mathrm{bcd}}$ \\
\hline & Day 19 & $0.00 \pm 0.00^{\mathrm{a}}$ & $0.50 \pm 0.71^{\mathrm{e}}$ & $4.54 \pm 0.01^{\mathrm{de}}$ \\
\hline & Day 20 & $0.00 \pm 0.00^{\mathrm{a}}$ & $0.00 \pm 0.00^{f}$ & $4.53 \pm 0.01^{\mathrm{de}}$ \\
\hline & Day 21 & $0.00 \pm 0.00^{\mathrm{a}}$ & $0.00 \pm 0.00^{f}$ & $4.52 \pm 0.02^{\mathrm{e}}$ \\
\hline
\end{tabular}

$\mathrm{PBS}=\mathrm{PBS}=$ phosphate-buffered saline;pro + typ $=$ both mixed probiotic cultures and Salmonella typ = mono Salmonella Typhimurium DT104. Data are means \pm SD from three replications and values followed by different letters within columns indicate significant differences $(p<0.05)$.

DT104 cells was significantly reduced from 2.30 to $0.00 \mathrm{log}$ $\mathrm{CFU} \cdot \mathrm{ml}^{-1}$. However, the noticeable effect of treatment with the combined potential probiotic LAB strains was observed from day 18 and onwards (Table 5).

Generally, the counts of Salmonella Typhimurium DT104 from the feces of the positive control group (typ) were consistently higher throughout the experiment of postinfection than from the feces of the probiotic-treated mice group (Table 5). Hence, when the selected potential probiotic LAB strains were administered at a dose of $\log 6$ CFUml $^{-1}$ level, Salmonella Typhimurium DT104 was eliminated from the feces of the probiotic-treated mice group at day 20 and onwards. Thus, in comparison with the results from Group I, there was no difference observed from days 20 and 21 with the mice treated with mixed probiotic strains since there was no viable cell count of the test pathogen in either (Table 5). But the recovery number of viable cell counts in feces of mice challenged only with Salmonella at day 20 was observed to be $4.53 \mathrm{log} \mathrm{CFU} \cdot \mathrm{ml}^{-1}$.

\section{Discussion}

The cross-streak plate method showed that the selected potential probiotic strains were found compatible. While assessing potential multi-strain probiotic cultures, it is essential to carry out compatibility tests in order to avoid the combining of strains showing antagonistic effects against each other. The present results are in agreement with those obtained by Sáez et al. [24], who reported that no inhibition halos of selected LAB cell-free supernatants against the other strains were observed, suggesting the absence of antimicrobial substances against each other that could inhibit their 
development when combined in a mixed culture form. Likewise, Mohamed et al. [30] have revealed that the 5 selected probiotic strains did not show any inhibitory effect to each other are expected to benefit the hosts without interfering with each other under in vivo conditions.

Probiotics have been successfully used for the prevention and treatment of various gastrointestinal diseases of humans and animals [31]. The beneficial effect of probiotic strains present in the fermented food products was recognized to have a nutritional and therapeutic effect on human health [22]. Several in vivo and in vitro studies have demonstrated that probiotics can inhibit Salmonella-associated diarrhea [16-18]. In the present study, the relevant functional characteristics of these potential probiotic LAB strains (Lactococcus lactis E124, Lactobacillus plantarum K132, Lactobacillus paracasei K114 and their combinations) showed effective inhibitory activities against Salmonella Typhimurium DT104 mainly in coculture experiments (Table 4).

All three potential probiotic strains and their combinations were able to remarkably inhibit the growth of Salmonella Typhimurium DT104 under in vitro conditions of the coculturing assay. The highest inhibition (100\%; $p<0.05)$ was observed with the combination of the three probiotic strains as in the form of mix 4 (Lactococcus lactis, Lactobacillus plantarum, and Lactobacillus paracasei). In agreement with this study, Adetoye et al. [32] have revealed that Lactobacillus salivarius C86 and Lactobacillus amylovorus C94 strains obtained from cattle feces were able to inhibit the growth of Salmonella spp. completely between 8 and 16 hours of coincubation with no recoverable Salmonella spp. in the growth medium. Different authors have also reported a strong inhibition of Salmonella spp. by potential probiotic LAB strains in the coculture assay $[16,33,34]$. In line with this, Potočnjak et al. [25] reported that all the tested Lactobacillus plantarum strains (A, B, and S1) were able to inhibit $(p<0.05)$ the growth of Salmonella Typhimurium at all-time points $(6,12$, and $24 \mathrm{~h})$ in the coculture assay. The same author reported that after $24 \mathrm{~h}$ of cocultivation, the number of Salmonella cells was reduced 1000 times in comparison with Salmonella monoculture and the inhibition was most pronounced after $12 \mathrm{~h}$ of coincubation and amounted to 97,98 , and $94 \%$ by strains $A, B$, and S1, respectively.

In the present study, oral administration of lactic acid bacteria to model mice caused complete inhibition of the test pathogen, particularly when used in combined form. Oral administration of potential probiotic LAB strains has a beneficial effect on maintaining and improving host health [35]. Viable probiotic strains are used in most probiotic studies, while few studies using heat-killed probiotic bacteria have been reported [36]. Several studies [16, 35, 37] indicated that probiotic $\mathrm{LAB}$ strains have protective effects against Salmonella infections by involving a number of possible mechanisms. Consequently, the protective mechanisms of inhibition by viable probiotic lactic acid bacteria encompass antimicrobial compounds produced by probiotic bacteria that kill enteric pathogens directly in the gastrointestinal tract [38], enhanced host intestinal immunity by increasing secretory IgA production to eliminate enteric pathogens [39] and competitive inhibition by binding to receptors used by pathogens on epithelial cells such as mannose and glycoproteins [40].

The mortality rate of the challenged mice with Salmonella Typhimurium DT104 was prevented by pretreatment with mixed probiotic LAB strains (Lactococcus lactis, Lactobacillus plantarum and Lactobacillus paracasei) using a mouse model. In agreement with the current study, Moura et al. [41] reported that the survival rate of mice supplemented with Lactobacillus acidophilus UFV-H2B20 and then infected with Salmonella Typhimurium was significantly $(p<0.05)$ higher in the experimental conventional group (34.6\% survival) compared to the control group (0\% survival). As observed with other studies [35], to assess the potential anti-Salmonella activity, mice were orally supplemented with a mixture of Lactobacillus plantarum for 10 days followed by infection with Salmonella Typhimurium SL1344. As a result, the survival rate of Lactobacillus plantarum-pretreated group was $60 \%$ at 15 days after infection, whereas that of the infected group was only $40 \%$. Moreover, Júnior et al. [37] have revealed that the higher survival rate $(70 \%)$ was observed in mice that were promptly treated with oral administration of Lactobacillus diolivorans $1 \mathrm{Z}$ and challenged with Salmonella Typhimurium in comparison with mice received only water $(0 \%$ survival) and then challenged with Salmonella Typhimurium.

In the present study, the mixed probiotic cultures eliminated the target organism from the feces of probiotictreated mice groups while administrated at $\log 6 \mathrm{CFU} / \mathrm{ml}$ inoculum level on day 20. However, the elimination of Salmonella Typhimurium DT104 took quite a long time in the experimental mice. This could be due to the time required for a probiotic strain to colonize the intestine and play their probiotic roles. On the contrary, mice without probiotics (typ) showed a high population of Salmonella Typhimurium DT104 on day 20. In general, regular consumption of fermented products containing probiotic cultures would result in the establishment of these cultures in the human intestine, which will help in rapid elimination of an enteric pathogen in the intestine. Furthermore, the reduction of intestinal Salmonella numbers due to the effects of probiotics was reported by different workers $[36,42,43]$. Salmonella Typhimurium ATCC 14028 was completely excluded within 23 days in mice when Lactobacillus rhamnosus and Lactobacillus plantarum were used as probiotics [29]. Similarly, oral administration of a combination of select lactic acid bacteria strains had a significant protective effect on Salmonella invasion and inflammation in broiler chicks [28].

Correspondingly, the mixed strains of Lactobacillus plantarum had preventive effects against Salmonella infection as they decreased Salmonella-induced animal deaths in a mouse model [35]. Administering a five-strain probiotic combination as either a milk fermentate or milk suspension for a total of 30 days significantly reduced Salmonella Typhimurium infection in probiotic-treated pigs at 15 days after infection [44]. Moreover, the protective effect of Lactobacillus rhamnosus GG against Salmonella infection in 
mice was significantly different at 4,7 , and 11 days after inoculation with Salmonella Typhimurium C5 [45].

\section{Conclusion}

Ethiopian fermented food products are rich in potential probiotic LAB strains that may exhibit antimicrobial efficacy against foodborne pathogens due to their bactericidal properties. In the present study, the selected potential probiotic LAB strains (Lactobacillus plantarum K132, Lactobacillus paracasei K114 and Lactococcus lactis E124) were able to show a protective effect against Salmonella Typhimurium DT104 infection in experimental mice. As a result, oral administration of the selected potential probiotic strains was able to protect mice against infection with Salmonella Typhimurium DT104 that suggests their promising potential be used for the production of functional fermented products.

\section{Data Availability}

The data used to support the findings of this study are included in the article and are available (the SAS data) from the corresponding author upon request.

\section{Conflicts of Interest}

The authors declare that they have no conflicts of interest.

\section{Acknowledgments}

The authors acknowledge the Department of Microbial, Cellular, and Molecular Biology, Addis Ababa University, Food Innovation and Health Institute Strategic Programme, Quadram Institute Bioscience, Norwich Research Park, Norwich, United Kingdom, for provision of all laboratory facilities, and Department of Biology, College of Natural and Computational Sciences, Aksum University, for financial support.

\section{References}

[1] D. Grace, Influencing Food Environments for Healthy Diets through Food Safety, FAO, Rome, Italy, 2016.

[2] S. P. Oliver, D. A. Patel, T. R. Callaway, and M. E. Torrence, "ASAS centennial paper: developments and future outlook for preharvest food safety1," Journal of Animal Science, vol. 87, no. 1, pp. 419-437, 2009.

[3] C. Lengsfeld, G. Faller, and A. Hensel, "Okra polysaccharides inhibit adhesion of Campylobacter jejuni to mucosa isolated from poultry in vitro but not in vivo," Animal Feed Science and Technology, vol. 135, no. 1-2, pp. 113-125, 2007.

[4] S. Sivapalasingam, C. R. Friedman, L. Cohen, and R. V. Tauxe, "Fresh produce: a growing cause of outbreaks of foodborne illness in the United States, 1973 through 1997," Journal of Food Protection, vol. 67, no. 10, pp. 2342-2353, 2004.

[5] N. A. Castillo, A. De Moreno De Leblanc, C. M. Galdeano, and G. Perdigón, "Comparative study of the protective capacity against Salmonella infection between probiotic and nonprobiotic lactobacilli," Journal of Applied Microbiology, vol. 114, no. 3, pp. 861-876, 2013.
[6] R. L. Santos, "Pathobiology of Salmonella, intestinal microbiota, and the host innate immune response," Frontiers in Immunology, vol. 5, p. 252, 2014.

[7] S. E. Majowicz, J. Musto, E. Scallan et al., "The global burden of nontyphoidal salmonella gastroenteritis," Clinical Infectious Diseases, vol. 50, no. 6, pp. 882-889, 2010.

[8] T. U. Berendonk, C. M. Manaia, C. Merlin et al., "Tackling antibiotic resistance: the environmental framework," Nature Reviews Microbiology, vol. 13, no. 5, pp. 310-317, 2015.

[9] A. M. Hammad and T. Shimamoto, "Towards a compatible probiotic-antibiotic combination therapy: assessment of antimicrobial resistance in the Japanese probiotics," Journal of Applied Microbiology, vol. 109, no. 4, pp. 1349-1360, 2010.

[10] M. Bhan, R. Bahl, and S. Bhatnagar, "Typhoid and paratyphoid fever," The Lancet, vol. 366, no. 9487, pp. 749-762, 2005.

[11] L. Birosova and M. Mikulasova, "Development of triclosan and antibiotic resistance in Salmonella enterica serovar typhimurium," Journal of Medical Microbiology, vol. 58, no. 4, pp. 436-441, 2009.

[12] S. D. Alcaine, L. D. Warnick, and M. Wiedmann, "Antimicrobial resistance in nontyphoidal Salmonella," Journal of Food Protection, vol. 70, no. 3, pp. 780-790, 2007.

[13] J. K. Das, D. Mishra, P. Ray et al., "In vitro evaluation of antiinfective activity of a Lactobacillus plantarum strain against Salmonella enterica serovar enteritidis," Gut Pathogens, vol. 5, no. 1, p. 11, 2013.

[14] C. Hill, F. Guarner, G. Reid et al., "The international scientific association for probiotics and prebiotics consensus statement on the scope and appropriate use of the term probiotic," Nature Reviews Gastroenterology \& Hepatology, vol. 11, no. 8, pp. 506-514, 2014.

[15] T. A. Oelschlaeger, "Mechanisms of probiotic actions-a review," International Journal of Medical Microbiology, vol. 300, no. 1, pp. 57-62, 2010.

[16] R. Dowarah, A. K. Verma, N. Agarwal, P. Singh, and B. R. Singh, "Selection and characterization of probiotic lactic acid bacteria and its impact on growth, nutrient digestibility, health and antioxidant status in weaned piglets," PLoS One, vol. 13, no. 3, Article ID e0192978, 2018.

[17] G. Tadesse, E. Ephraim, and M. Ashenafi, "Assessment of the antimicrobial activity of lactic acid bacteria isolated from borde and shamita, traditional Ethiopian fermented beverages, on some foodborne pathogens and effect of growth medium on the inhibitory activity," Internet Journal of Food Safety, vol. 5, pp. 13-20, 2005.

[18] A. Tesfaye, T. Mehari, and M. Ashenafi, "Evaluation of the in vitro and in vivo probiotic qualities of lactic acid bacteria (LAB) recovered from locally fermented products," International Journal of Probiotics \& Prebiotics, vol. 6, no. 2, 2011.

[19] G. Reid, J. Jass, M. T. Sebulsky, and J. K. McCormick, "Potential uses of probiotics in clinical practice," Clinical Microbiology Reviews, vol. 16, no. 4, pp. 658-672, 2003.

[20] C. N. Jacobsen, V. Rosenfeldt Nielsen, A. E. Hayford et al., "Screening of probiotic activities of forty-seven strains of Lactobacillus spp. by in vitro techniques and evaluation of the colonization ability of five selected strains in humans," $A p$ plied and Environmental Microbiology, vol. 65, no. 11, pp. 4949-4956, 1999.

[21] H. M. Timmerman, C. J. M. Koning, L. Mulder, F. M. Rombouts, and A. C. Beynen, "Monostrain, multistrain and multispecies probiotics-a comparison of functionality and efficacy," International Journal of Food Microbiology, vol. 96, no. 3, pp. 219-233, 2004. 
[22] A. L. Meyer, I. Elmadfa, I. Herbacek, and M. Micksche, "Probiotic, as well as conventional yogurt, can enhance the stimulated production of proinflammatory cytokines," Journal of Human Nutrition and Dietetics, vol. 20, no. 6, pp. 590-598, 2007.

[23] K. Pedersen and G. W. Tannock, "Colonization of the porcine gastrointestinal tract by lactobacilli," Applied and Environmental Microbiology, vol. 55, no. 2, pp. 279-283, 1989.

[24] G. D. Sáez, L. Flomenbaum, and G. Zárate, "Lactic acid bacteria from argentinean fermented foods: isolation and characterization for their potential use as starters for fermentation of vegetables," Food Technology and Biotechnology, vol. 56, no. 3, p. 398, 2018.

[25] M. Potočnjak, P. Pušić, J. Frece et al., "Three new Lactobacillus plantarum strains in the probiotic toolbox against gut pathogen Salmonella enterica serotype typhimurium," Food Technology and Biotechnology, vol. 55, no. 1, pp. 48-54, 2017.

[26] S.-M. Lim and D.-S. Im, "Screening and characterization of probiotic lactic acid bacteria isolated from Korean fermented foods," Journal of Microbiology and Biotechnology, vol. 19, no. 2, pp. 178-186, 2009.

[27] K. Truusalu, P. Naaber, T. Kullisaar et al., "The influence of antibacterial and antioxidative probiotic lactobacilli on gut mucosa in a mouse model of Salmonella infection," Microbial Ecology in Health and Disease, vol. 16, no. 4, pp. 180-187, 2004.

[28] C.-Y. Chen, H.-Y. Tsen, C.-L. Lin, B. Yu, and C.-S. Chen, "Oral administration of a combination of select lactic acid bacteria strains to reduce the Salmonella invasion and inflammation of broiler chicks," Poultry Science, vol. 91, no. 9, pp. 2139-2147, 2012.

[29] T. Setyawardani, W. Rahayu, N. Palupi, and J. Sumarmono, "The potential of Lactobacillus rhamnosus and Lactobacillus plantarum isolated from goat's milk in inhibiting Salmonella typhimurium ATCC 14028 infections in rats," International Food Research Journal, vol. 24, no. 6, pp. 2625-2631, 2017.

[30] W. mohamed, O. Rabeea, H. AbuShady, and H. Youssef, "Development of novel multispecies probiotic mixture," The Egyptian Journal of Experimental Biology (Botany), vol. 13, no. 2, pp. 245-258, 2017.

[31] D. Fayol-Messaoudi, C. N. Berger, M.-H. Coconnier-Polter, V. Lievin-Le Moal, and A. L. Servin, " $p H$-, Lactic acid-, and non-lactic acid-dependent activities of probiotic Lactobacilli against Salmonella enterica serovar typhimurium," Applied and Environmental Microbiology, vol. 71, no. 10, pp. 60086013, 2005.

[32] A. Adetoye, E. Pinloche, B. A. Adeniyi, and F. A. Ayeni, "Characterization and anti-salmonella activities of lactic acid bacteria isolated from cattle faeces," BMC Microbiology, vol. 18, no. 1, p. 96, 2018.

[33] A. Abdel-Daim, N. Hassouna, M. Hafez, M. S. A. Ashor, and M. M. Aboulwafa, "Antagonistic activity of Lactobacillus isolates against Salmonella typhi in vitro," BioMed Research International, vol. 2013, Article ID 680605, 12 pages, 2013.

[34] M. M. Coman, M. C. Verdenelli, C. Cecchini et al., "In vitroevaluation of antimicrobial activity of Lactobacillus rhamnosus IMC 501, Lactobacillus paracasei IMC 502 and SYNBIO against pathogens," Journal of Applied Microbiology, vol. 117, no. 2, pp. 518-527, 2014.

[35] J. Liu, D. Hu, Y. Chen et al., "Strain-specific properties of Lactobacillus plantarum for prevention of Salmonella infection," Food \& Function, vol. 9, no. 7, pp. 3673-3682, 2018.

[36] H. Ishikawa, E. Kutsukake, T. Fukui et al., "Oral administration of heat-killed Lactobacillus plantarum strain b240 protected mice against Salmonella enterica serovar typhimurium," Bioscience, Biotechnology, and Biochemistry, vol. 74, no. 7, pp. 1338-1342, 2010.

[37] M. A. Júnior, S. H. C. Sandes, M. F. Ricci et al., "Protective effect of Lactobacillus diolivorans 1Z, isolated from Brazilian kefir, against Salmonella enterica serovar typhimurium in experimental murine models," Frontiers in Microbiology, vol. 9, 2018.

[38] Y. Aiba, N. Suzuki, A. M. A. Kabir, A. Takagi, and Y. Koga, "Lactic acid-mediated suppression of Helicobacter pylori by the oral administration of Lactobacillus salivarius as a probiotic in a gnotobiotic murine model," The American Journal of Gastroenterology, vol. 93, no. 11, pp. 2097-2101, 1998.

[39] M. V. Tejada-Simon, J. H. Lee, Z. Ustunol, and J. J. Pestka, "Ingestion of yogurt containing Lactobacillus acidophilus and Bifidobacterium to potentiate immunoglobulin A responses to cholera toxin in mice," Journal of Dairy Science, vol. 82, no. 4, pp. 649-660, 1999.

[40] H. H. Chiu, C. C. Tsai, H. Y. Hsih, and H. Y. Tsen, "Screening from pickled vegetables the potential probiotic strains of lactic acid bacteria able to inhibit the Salmonella invasion in mice," Journal of Applied Microbiology, vol. 104, no. 2, pp. 605-612, 2008.

[41] L. N. Moura, E. Neumann, L. Q. Vieira, and J. R. Nicoli, "Protection by Lactobacillus acidophilus UFV-H2B20 against experimental oral infection with Salmonella enterica subsp. enterica ser. typhimurium in gnotobiotic and conventional mice," Brazilian Journal of Microbiology, vol. 32, no. 1, pp. 66-69, 2001.

[42] J. W. Collins, N. G. Coldham, F. J. Salguero et al., "Response of porcine intestinal in vitro organ culture tissues following exposure to Lactobacillus plantarum JC1 and Salmonella enterica serovar typhimurium SL1344," Applied and Environmental Microbiology, vol. 76, no. 19, pp. 6645-6657, 2010.

[43] J. S. Eom, J. Song, and H. S. Choi, "Protective effects of a novel probiotic strain of Lactobacillus plantarum JSA22 from traditional fermented soybean food against infection by Salmonella enterica serovar typhimurium," Journal of Microbiology and Biotechnology, vol. 25, no. 4, pp. 479-491, 2015.

[44] P. G. Casey, G. E. Gardiner, G. Casey et al., "A five-strain probiotic combination reduces pathogen shedding and alleviates disease signs in pigs challenged with Salmonella enterica serovar typhimurium," Applied and Environmental Microbiology, vol. 73, no. 6, pp. 1858-1863, 2007.

[45] S. Hudault, V. Liévin, M. F. Bernet-Camard, and A. L. Servin, "Antagonistic activity exerted in vitro and in vivo by Lactobacillus casei (strain GG) against Salmonella typhimurium C5 infection," Applied and Environmental Microbiology, vol. 63, no. 2, pp. 513-518, 1997. 